- network of bottom-moored instruments will begin to record water temperature and salinity at different levels in the deep, cold currents that run along the edges of the ocean basin. By combining those data with acoustic measurements of current velocity and bottom pressure, and with temperature and salinity data recorded by freely drifting profiling floats in the open ocean, scientists should be able to calculate the strength of the overturning circulation at that latitude, says Silvia Garzoli, chief scientist at the Atlantic Oceanographic and Meteorological Laboratory in Miami, Florida, and a member of the project's executive committee.

Most scientists regard the idea that global warming will trigger a collapse of ocean circulation - the apocalyptic scenario that inspired the 2004 action film The Day After Tomorrow — to be exceedingly unlikely. But Bryden says that the 2009 Atlantic circulation glitch is an indication of just how surprising ocean behaviour can be. "The next one," he says, "may be twice as big." -

1. Cunningham, S. A. et al. Science $\mathbf{3 1 7}, \mathbf{9 3 5 - 9 3 8}$ (2007).

2. McCarthy, G. et al. Geophys. Res. Lett. 39, L19609 (2012).

3. Meehl, G. A. et al. in Climate Change 2007: The Physical Science Basis (eds Solomon, S. et al.) Ch. 10 (Cambridge Univ. Press, 2007).

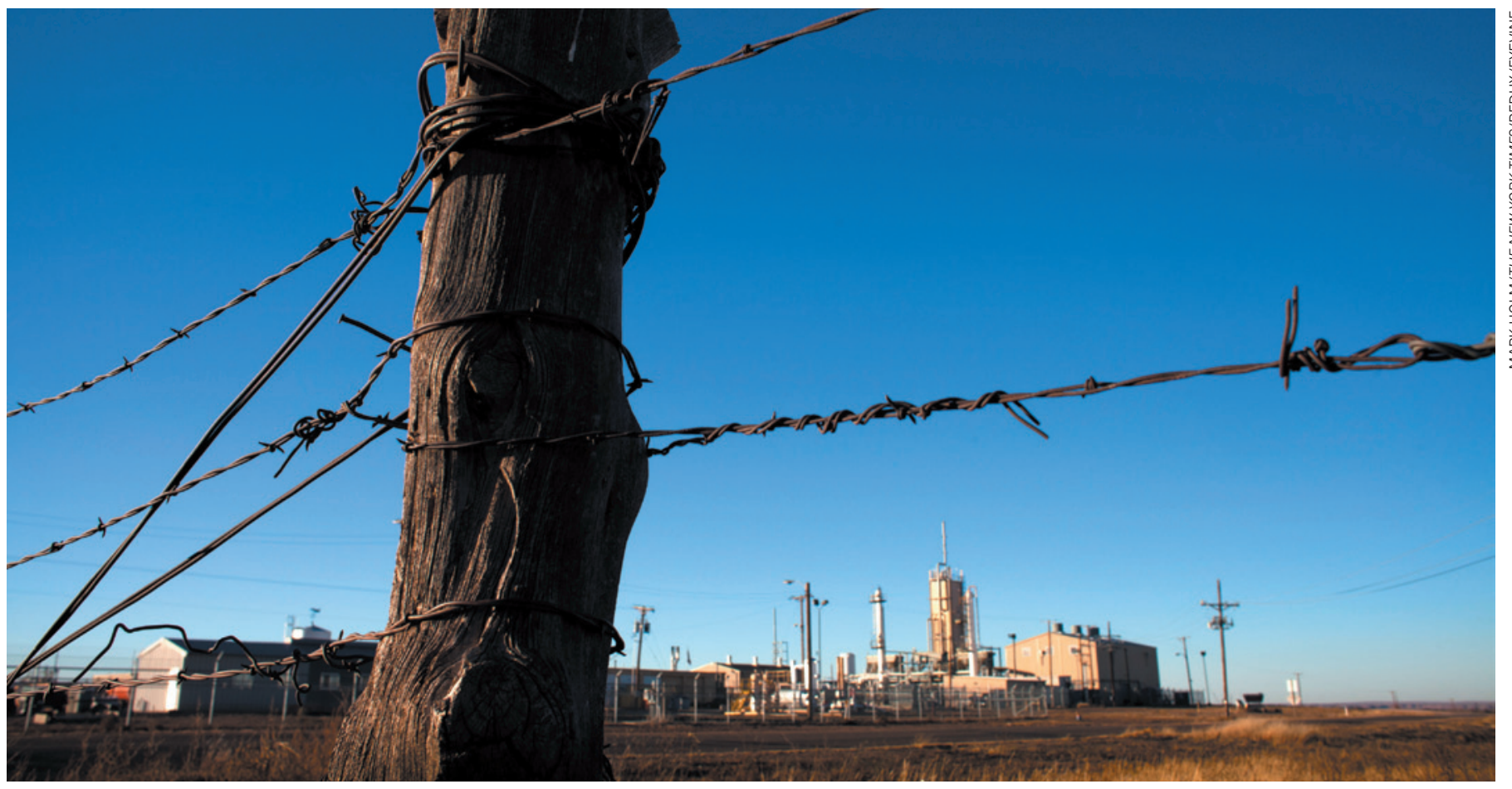

The US Federal Helium Reserve was scheduled to end sales of the gas — but they may now continue at higher prices.

GLOBAL RESOURCES

\title{
US bill would keep helium store afloat
}

\section{Russia and Qatar prepare to dominate market as gas price inflation puts researchers under pressure.}

\section{BY MARK PEPLOW}

$\mathrm{U}$ S lawmakers have taken a significant step towards averting a global crisis in helium supply, thanks to a bill passed by the House of Representatives on 26 April. If it passes the Senate and becomes law, the bill would delay the imminent closure of the world's only strategic helium reserve. It would also increase the price of the gas from the reserve, so helium-dependent researchers and industry could still face ballooning costs. However, the prospect of higher prices is encouraging the development of new helium sources in Qatar and Russia, which may ultimately lead to a more stable helium market.

With a boiling point of 4 kelvin - lower than that of any other element - liquid helium has many uses, including cooling the superconducting magnets in medical imaging scanners. The semiconductor industry also relies on the inert gas to shield delicate crystals from contaminants during manufacturing.

Demand is on the rise. More than 100 million cubic metres of helium is extracted from natural gas worldwide every year, yet meeting global needs requires a further 60 million cubic metres a year from the US Federal Helium Reserve, a vast geological reservoir near Amarillo, Texas, that stores helium from past gas extraction (see 'Floating skyward').

In the mid-1990s, the reserve boasted 1 billion cubic metres of the gas - and a debt of US $\$ 1.3$ billion accrued after a large buy-up of helium in the 1960s. Over time, the simple formula used to calculate the price of helium sold from the reserve has failed to keep pace with commercial prices. In 1996, appalled that the government was undercutting a booming commercial gas market, lawmakers passed the Helium Privatization Act. Its goal was to sell $\rightarrow$ NATURE.COM

For more on helium supply, visit: go.nature.com/fuh4jd the helium reserve to pay off the debt. Once the debt was gone, no more helium would be sold. "They would literally 


\section{FLOATING SKYWARD}

The price of helium from a US government stockpile has not kept pace with commercial prices (see graph). Most helium currently comes from the United States, but with price rises expected to continue, Russia is planning to tap its reserves, and other countries may increase production (see map).

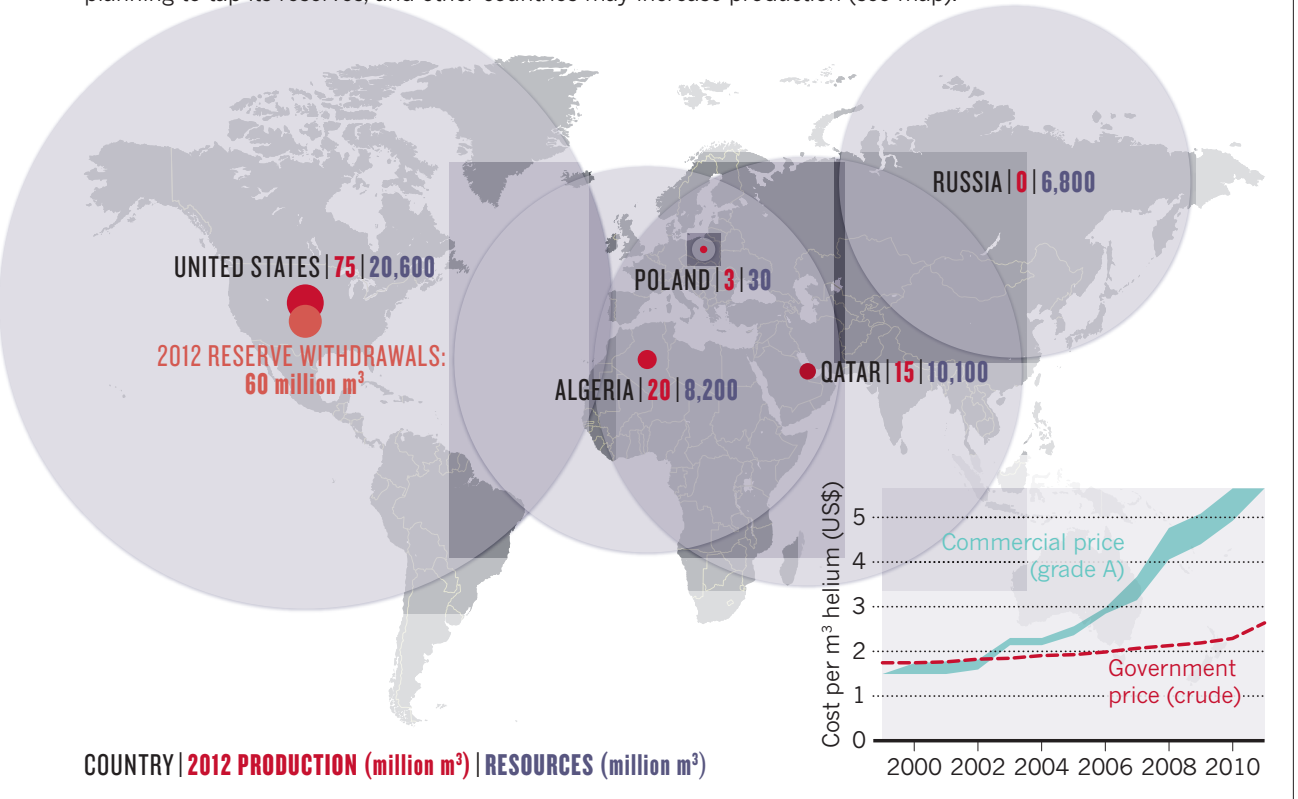

turn off the tap," says Richard Clarke, a process and resources consultant based in Oxford, UK. The shutdown was expected by October this year. And because the reserve's cut-rate prices had dissuaded companies from developing sources elsewhere, a supply shortage was possible. "The Privatization Act has come back to bite them," says Clarke.

Alarmed, researchers and high-tech industries lobbied Congress to keep the helium flowing. Congress responded: the Responsible Helium Administration and Stewardship Act passed by the House maps out a more orderly shutdown. A similar bill has been introduced to the Senate; if it passes this summer, as is expected, and the law takes effect, the stockpile would be sold to the highest bidders in semiannual auctions, until just 85 million cubic metres are left. Experts say that point might be reached in 2020, and prices could rise by $50 \%$ in that time.

The remaining stock would be available only to government users such as NASA. "The United States will have ceased to be the major player in helium production," says William Nuttall, an energy expert at the Open University in Milton Keynes, UK. Users will increasingly depend on helium from gas fields in Qatar, Algeria and Russia.

The Russian energy giant Gazprom aims to capture the lion's share of the market. Last year, the global business consultancy Ernst \& Young, based in London, estimated that gas fields in eastern Siberia could produce 250 million cubic metres of crude helium per year by 2030, satisfying at least three-quarters of projected demand. One of the most promising resources is the Chayandinskoye natural-gas field, which contains a relatively rich bounty of about $0.5 \%$ helium. In the past six months, Gazprom has signed cooperation agreements with many of the leading companies that purify and supply helium, including Air Liquide, Linde and Matheson. Helium could start to flow from Chayandinskoye by 2018 .

In Qatar, extra helium-production capacity is scheduled to come online this year. The Ras Laffan Helium 2 plant could enable the country to meet up to $25 \%$ of global helium demand - although much of its output will head east to serve the growing Asian market, says Clarke.

And private efforts in the United States seem to be ramping up. In March, Flatirons Resources of Denver, Colorado, received approval from the US Bureau of Land Management to develop a small well designed to tap helium from a Utah natural-gas field - the first US well devoted solely to helium.

Helium may not run short, but the price increases will hurt labs, says Jodi Lieberman, senior government-relations specialist at the American Physical Society, headquartered in College Park, Maryland. Some low-temperature physicists already spend up to $70 \%$ of their grants on the gas, she adds.

In a 2010 report, Selling the Nation's Helium Reserve, the US National Academy of Sciences (NAS) recommended that funding agencies help researchers to buy cooling systems that recycle helium, or reduce its consumption. So far, cash-strapped funders have not had the resources to make the expensive equipment widely available, says James Lancaster, NAS study director for the report.

But as prices float skyward, helium-sparing equipment may start to look like a necessity. 